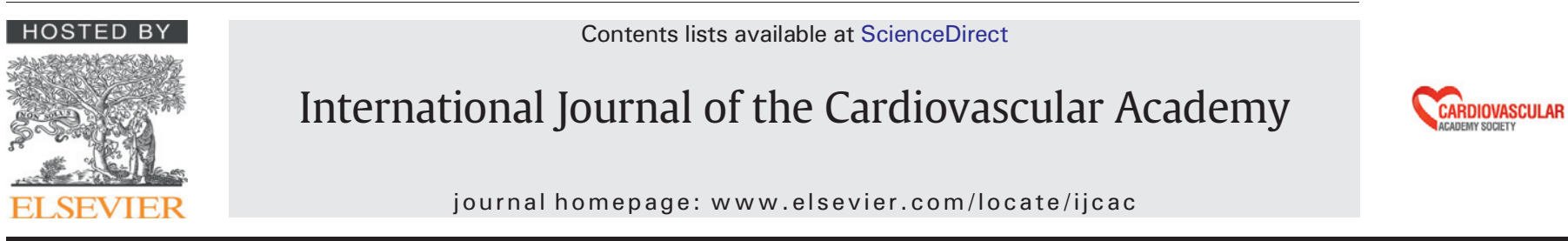

Short communication

\title{
Syphilitic aortic aneurysm in a young hepatitis B-infected man: Case presentation
}

\author{
Yeşim Hoşcan * \\ Private OFM Hospital, Department of Cardiology, Antalya, Turkey
}

\section{A R T I C L E I N F O}

\section{Article history:}

Received 13 May 2015

Received in revised form 21 July 2015

Accepted 21 July 2015

Available online 4 September 2015

\section{Keywords:}

Aneurysm

Aort

Syphilis

\begin{abstract}
A B S T R A C T
Syphilitic aortit is a common manifestation of syphilis, involving the thoracic aorta, where destruction of elastic tissue in the media results in dilation and aneurysm formation. We report and identified a case of a 38-year old patient who presents a large ascending aorta aneurysm. He continues to carry the hepatitis B virus. The CT angiogram confirmed the presence of a giant fusiform ascending aortic aneurysm measuring $86 \mathrm{~mm}$ of maximum diameter extending nearly to the origin of the brachiocephalic artery with normal diameter across the descending thoracic and abdominal aorta and no flow-limiting obstruction or significant atherosclerotic disease of the supraaortic arteries. The definitive treatment of aortic aneurysm is surgical repair. Surgery and specific antibiotic treatment do not exclude future manifestations of the disease, even after erradication of the T. pallidum, which makes permanent follow-up needed.

(C) 2015 The Society of Cardiovascular Academy. Production and hosting by Elsevier B.V. All rights reserved. This is an open access article under the CC BY-NC-ND license (http://creativecommons.org/licenses/by-nc-nd/4.0/).
\end{abstract}

Syphilitic aortic aneurysm is a rare occurrence in the antibiotic era, making the diagnosis assumption even more infrequent. We report a case of a 38-year old patient who presents a large ascending aorta aneurysm is identified.

\section{Case presentation}

A 38-year old patient, without previous medical events of note, presented at the emergency department with sudden chest pain and nausea. The patient had no known history of hypertension, dyslipidaemia, tobacco abuse and ethylism. The haemogram, blood chemistry and coagulation tests were unremarkable and the viral markers tested negative for human immunodeficiency virus (HIV) 1 and 2, hepatitis $C$ except hepatitis b. He continues to carry the hepatitis B virus. The EKG was consistent with left ventricular hypertrophy without signs of cardiac ischemia. The echocardiogram was conducted to evaluate a significant ascending aorta ectasia with severe aortic insufficiency and moderate left ventricular hypertrophy, with poor left ventricular systolic function. The CT angiogram confirmed the presence of a giant fusiform ascending aortic aneurysm measuring $86 \mathrm{~mm}$ of maximum diameter extending nearly to the origin of the brachiocephalic artery with normal diameter across the descending thoracic and abdominal aorta and no flow-limiting obstruction or significant atherosclerotic disease of the supra-aortic arteries (Fig. 1a and b). The patient tested

\footnotetext{
* Tel.: +90 532 3481702; fax: +902423354011.

E-mail address: yucarci@yahoo.com.

Peer review under responsibility of The Society of Cardiovascular Academy.
}

positive for Treponema pallidum particle agglutination (TPHA) on blood and negative for venereal disease research laboratory (VDRL) test on blood. In this clinical scenario, the patient was diagnosed with syphilis with cardiovascular involvement and was treated with penicillin. The patient recovered completely within 1 week. The cardiovascular involvement was limited to the ascending aorta, with no flow-limiting disease in the coronary angiogram. The size and aetiology of the aneurysm indicated surgical treatment. Patients were operated successfully.

\section{Discussion}

Syphilis is a bacterial sexually transmitted disease caused by the spirochete $T$. pallidum, subspecies pallidum, which had developed as a new world disease out of evolving treponemal species. ${ }^{1}$ The disease progresses through primary, secondary, and tertiary phases. Involvement of the cardiovascular system is the most dangerous sequela of the tertiary phase (late syphilis).

The ascending aorta is most often affected (in $50 \%$ of cases), followed by (in decreasing order of incidence) the aortic arch, the descending aorta, and the abdominal aorta. The rarity of this aetiology makes the diagnosis difficult, mainly because syphilis testing is not routinely used. In late syphilis, non-treponemal tests like VDRL test and rapid plasma reagin test are less sensitive (71-73\%), when compared with Treponema-specific tests such as TPHA, microhaemagglutination test, fluorescent treponemal antibody absorption test (94-96\%)., In the presence of an aortic aneurysm, particularly in younger patients, syphilitic serological testing is advised. ${ }^{3} \mathrm{CT}$ angiogram is the best imaging study to define the size and anatomy of the aneurysm, but in the setting of an aneurysm, the echocardiogram and coronary angiogram are 


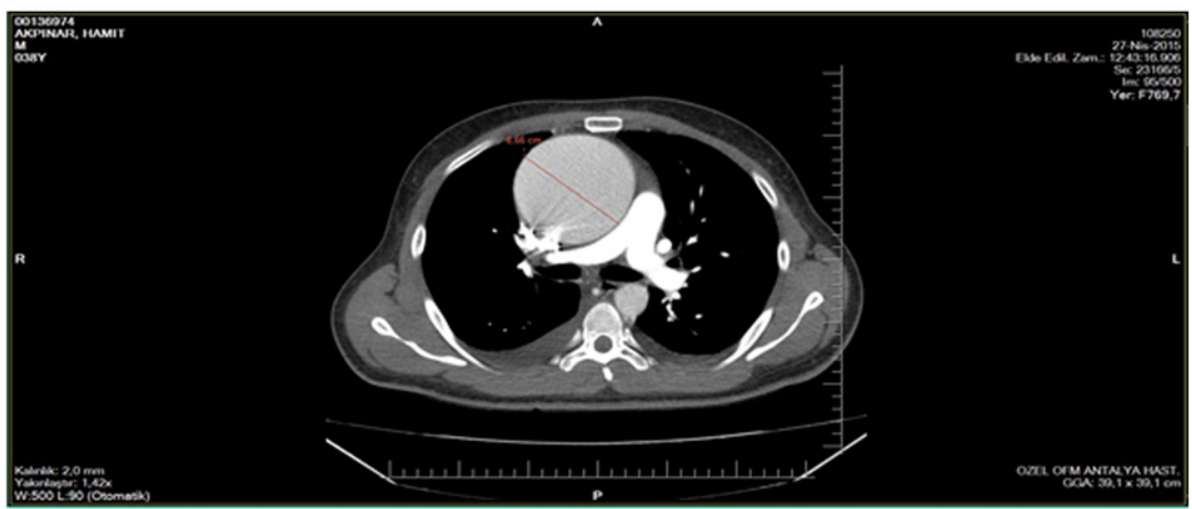

(a)

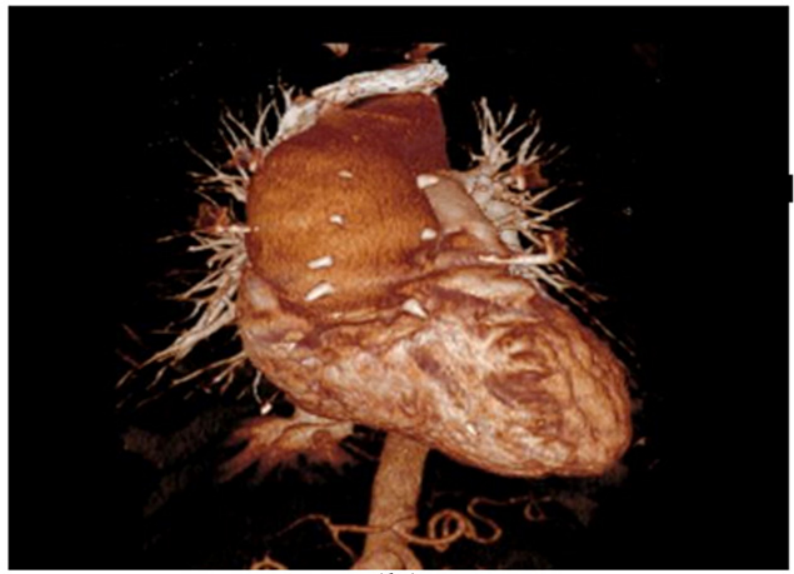

(b)

Fig. 1. CT images of the ascending aorta aneurysm.

mandatory to exclude aortic regurgitation and coronary flow-limiting lesions. ${ }^{4,5}$ The definitive treatment of aortic aneurysm is surgical repair. Surgery and specific antibiotic treatment does not exclude future manifestations of the disease, even after erradication of the T. pallidum, which makes permanent follow-up needed. ${ }^{4,6}$

\section{References}

1. Harper KN, Ocampo PS, Steiner BM, et al. On the origin of the treponematoses: a phylogenetic approach. PLoS Negl Trop Dis Jan 15 2008;2(1):e148.
2. Larsen SA, Steiner BM, Rudolph AH. Laboratory diagnosis and interpretation of tests for syphilis. Clin Microbiol Rev 1995;8:1-21.

3. Tichonova L, Borisenko K, Ward H, et al. Epidemics of syphilis in the Russian Federation: trends, origins and priority of control. Lancet 1997;350:210-213.

4. Duncan JM, Cooley DA. Surgical considerations in aortitis. Part III: syphilitic and other forms of aortitis. Tex Heart Inst J 1983;10:337-341.

5. Jackman JD, Radolf JD. Cardiovascular syphilis. Am J Med 1989;87:425-433.

6. Salas Millán J, Martínez Calzón JL, et al. Cardiovascular syphilis: a case report. Rev Esp Cardiol 2000;53:1656-1658. 